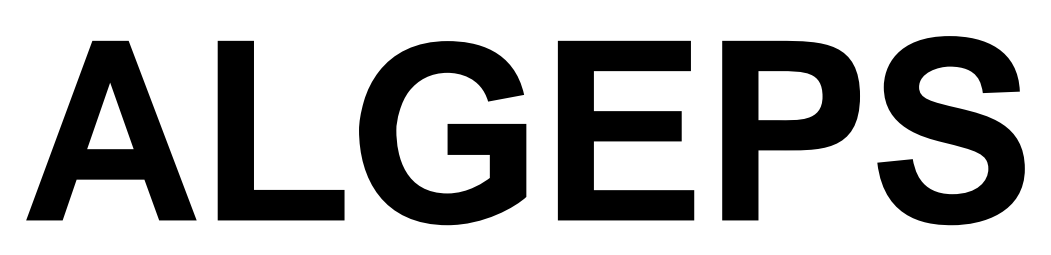

REVISTA DE GEOLOGIA, SĖRIE B no 594 - Juny del 2012

ISSN $1132-7014$

D.L.B. 28.178 - 92

14 pàgines

\begin{abstract}
RECORRIDO DESDE BIELSA A PLAN Y AL HOSPITAL DE GISTAÍN, A TRAVÉS DEL PATRIMONIO GEOLÓGICO Y MINERO DE LA COMARCA DEL SOBRARBE
\end{abstract}

Josep M. Mata-Perelló

Aquest recorregut va ésser experimentat amb docents el dia 19 DE JUNY DEL 2010 


\section{RECORRIDO DESDE BIELSA A PLAN Y AL HOSPITAL DE GISTAÍN, A TRAVÉS DEL PATRIMONIO GEOLÓGICO Y MINERO DE LA COMARCA DEL SOBRARBE}

\section{ADVERTENCIAS PREVIAS}

Al igual que en otros ITINERARIOS GEOLÓGICOS Y MINERALÓGICOS, se van a presentar una serie de PARADAS, en las cuales se tratarán cuestiones relacionadas con la mineralogía (y con la geología de la zona, o del lugar). Junto a ellas, se presentaran también las denominadas PARADAS-CONDICIONALES. Pues bien, de estas puede prescindirse sino se dispone del tiempo suficiente, para desarrollar todo el recorrido del itinerario.

En esta ocasión, presentamos un recorrido en el cual las características geológicas y mineralógicas, se van a compaginar con las relacionadas con el inmenso PATRIMONIO MINERO DEL ALTO SOBRARBE.

Por otra parte, si bien la mayoría de los recorridos se van a efectúan por caminos y carreteras en buen estado de conservación, no será así en todos los casos. Por ello, sería muy conveniente de buscar la información necesaria, sobre el estado de los caminos, antes de emprender la marcha.

$Y$, al igual que hemos hecho en otros recorridos de este tipo, queremos pedir a todos los participantes, el máximo respeto hacia nuestra querida NATURALEZA, de la cual también formamos parte.

\section{BREVE INTRODUCCIÓN GEOLÓGICA}

En esta ocasión, el recorrido del itinerario discurrirá íntegramente por el Sistema Pirenaico; y más concretamente por sus sectores centrales, por los denominados Apilamientos Antiformes de la Zona Axial del Sistema Pirenaico. Sin embargo, el recorrido se iniciará en la zona más septentrional del Manto de Gavarnié, por él discurrirá por los alrededores de Bielsa; entre esta población y las inmediaciones de Salinas (Salinas de sin y Salinas de Bielsa).

Posteriormente, el recorrido recalará en el extremo septentrional del Manto de Cotiella, por el que se circulará entre las inmediaciones de Salinas y las de Plan. El resto del recorrido, precisamente el correspondiente a la parte fundamental del itinerario, se desarrollará por los denominados Apilamientos Antiformes de la Zona Axial del Sistema Pirenaico. Este es el caso de los recorridos que efectuaremos entre Plan, San Juan de Plan, Gistaín y el Hospital de Gistaín 


\section{BREVE INTRODUCCIÓN GEOGRÁFICA}

El recorrido del presente itinerario se efectuará exclusivamente por una comarca aragonesa, por la del Sobrarbe. Así el recorrido se iniciará en la población de Bielsa (la capital del denominado Alto Sobrarbe), recorriendo la parte septentrional comarcal hasta llegar al Hospital de Gistaín.

Por otro lado, la totalidad del recorrido transitará por la cuenca del río Cinca, Los primeros trayectos se efectuaran siguiendo el cauce de este río, en sentido descendente, desde Bielsa a Salinas.

A partir de este lugar, el recorrido irá remontando siempre el río Cinqueta (afluente del anterior). Esto ocurrirá a partir de Salinas y hasta llegar al fin del recorrido en el Hospital de Gistaín.

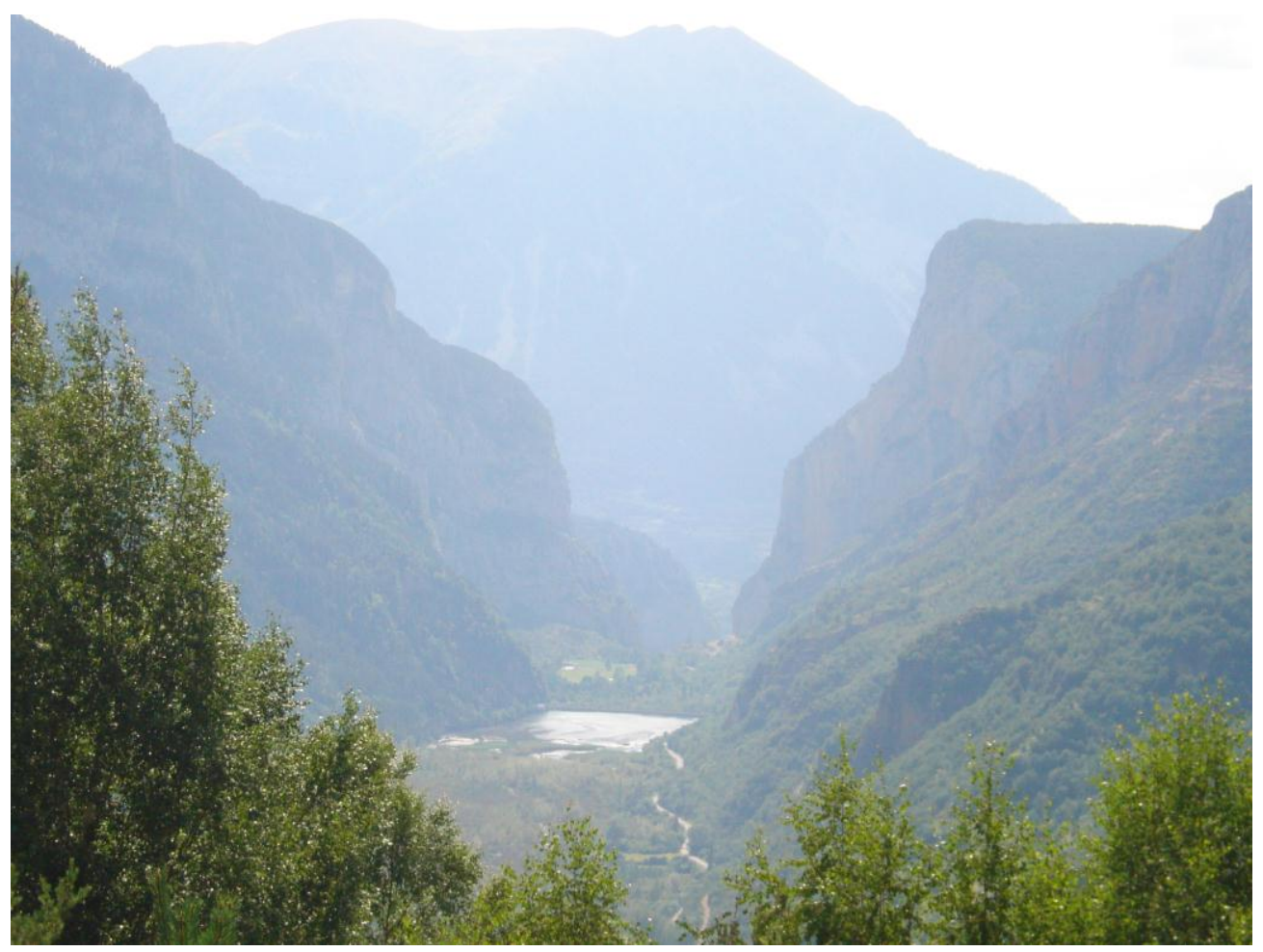

El Valle de Chistau, desde las Minas del Yerri

\section{OBJETIVOS GENERALES DE ESTE ITINERARIO}

En este itinerario, los objetivos generales que se han de conseguir, se pueden concretar en los siguientes aspectos:

1.- Observación y estudio de los materiales mesozoicos (fundamentalmente del Triásico Superior; y en menor grado del Cretácico), que constituyen los relieves del Manto de Gavarnié, por donde se transitará entre las inmediaciones de Bielsa y Salinas de Sin.

2.- Observación y estudio de los materiales mesozoicos (fundamentalmente del Triásico Superior; y en menor grado del Jurásico y del Cretácico), que constituyen los 
relieves de las zonas septentrionales del Manto del Cotiella, por donde se transitará por las inmediaciones de Salinas de Sin., hasta casi las inmediaciones de Plan.

3.- Observación y estudio de los materiales paleozoicos (fundamentalmente del Ordoviciense), que forman parte de las Apilamientos Antiformes de la Zona Axial Pirenaica. Cabe recordar que buena parte del recorrido del itinerario se efectuará por esta subunidad, especialmente entre Plan, San Juan de Plan y el Hospital de Gistaín

4.- Observación de las estructuras pirenaicas anteriormente mencionadas, y de las relaciones existentes entre ellas.

5.- Observación de las diferentes mineralizaciones situadas a lo largo del recorrido del presente itinerario. Estos indicios se relacionan con:

5A) las mineralizaciones filonianas asociadas a fracturas, de características $P b-Z n-F$. Se encuentran situadas en diferentes lugares del término de Bielsa, en las Minas de Serveto. En todos estos lugares, se hallan encajadas entre los materiales del Ordoviciense, dentro de los Apilamientos Antiformes de la Zona Axial Pirenaica.

5B) las mineralizaciones filonianas asociadas a fracturas, de características Co-Ni. Se encuentran situadas en el Yerri (San Juan de Plan). Como en el caso anterior se hallan encajadas entre los materiales del Devónico, dentro de los Apilamientos Antiformes de la Zona Axial Pirenaica

6.- Observación de las explotaciones mineras, desarrolladas a partir de las mineralizaciones citadas en el apartado anterior.

7.- Observación de los distintos PIPM (Puntos de Interés del Patrimonio Minero) relacionados con las antiguas explotaciones mineras desarrolladas en esta zona; así como con las características de las propias mineralizaciones.

8.- Observación de los distintos PIG (Puntos de Interés del Patrimonio Geológico) que iremos encontrando a lo largo del recorrido del itinerario. En este caso mencionaremos el de la Inclusa (Plan).

9.- Estudio y observación de los impactos producidos sobre el Patrimonio Natural, a partir de las explotaciones mineras. Y, al mismo tiempo, observación de las restauraciones efectuadas, si se da el caso.

\section{ANTECEDENTES BIBLIOGRÁFICOS}

Existen pocos antecedentes bibliográficos, relacionados con el desarrollo de este itinerario. No obstante, mencionaremos los correspondientes a varios itinerarios, los cuales se desarrollan por estos lares. Unos y otros, son parcialmente coincidentes con el que ahora presentamos. Estos antecedentes, son los siguientes: MATA-PERELLÓ (1995, 1996, 1997a y 1997b). Otro antecedente, cabe encontrarlo en el trabajo de MATA-PERELLÓ y SANZ-BALAGUÉ (1993).

Por otra parte, haremos mención de algunos trabajos, de carácter geológico generalista, que corresponden a los trabajos del IGME (1972, 1974 y 1975), relativos al 
Mapa Geológico de España (a Escala 1.200.000), al Mapa Metalogenético de España y al Mapa de Rocas Industriales de España.

Con respecto a las mineralizaciones que iremos encontrando, mencionaremos los trabajos de: CALVO et altri (1988); MAESTRE (1845); así como nuestros trabajos: MATA-PERELLÓ (1987 y 1992). En relación con el patrimonio minero de estas mineralizaciones, cabe citar los trabajos de VIVEZ (1997a y 1997b).

También mencionaremos el trabajo de PRAMES (2005) dedicado a la comarca del Sobrarbe. Así como el del GOBIERNO DE ARAGÓN (2001), dedicado a los Puntos de Interés Geológico de Aragón.

Finalmente, diremos que todos estos trabajos (así como otros que ahora no hemos aludido), figurarán mencionados, por orden alfabético, en el apartado dedicado a las REFERENCIAS BIBLIOGRÁFICAS.

\section{RECORRIDO DEL ITINERARIO}

El recorrido del itinerario se iniciará en la población de Bielsa, Desde ahí, por la carretera autonómica A-139 se bajará hacia Salinas (el conjunto de Salinas de Sin y Salinas de Bielsa). En este tramo se realizaran dos paradas.

Luego, en Salinas se tomará la carretera A-2609, hacía el Este. Por ella se pasará pronto por los cruces de Saravillo (por la derecha) y de Sin. En las inmediaciones de los cruces se hará una nueva parada. Luego el recorrido se dirigirá hacía Plan, por 1 carretera antes mencionada, realizándose una parada en el Congosto de la Inclusa.

Tras ello, el recorrido seguirá hasta Plan desde donde se irá a San Juan de Plan. Desde este pueblo se tomará cerca del Puente de Pescadores, el camino que asciende hacía las cercanías de las Minas de Cobalto del Yerri. Por ese sector se realizaran dos nuevas paradas, una en las minas y otra en el descargador - antigua fundición.

Tras ello, se retornará a San Juan de Plan, para seguir río arriba remontando el Cinqueta, hasta llegar al Hospital de Gistaín, aunque antes habremos dejado (por la izquierda) la carretera de Gistaín. Finalmente, iremos a las Minas de Plomo del Hospital de Gistaín, en donde se realizará la última parada.

\section{DESCRIPCIÓN DEL ITINERARIO}

Como de costumbre, estructuraremos el recorrido del itinerario en una serie de "estaciones" o PARADAS, que iremos viendo a continuación En cada una de estos parones efectuaremos un breve comentario (geológico o mineralógico, según corresponda). Asimismo, las paradas se referirán siempre a algún paraje geográfico, indicándose también los siguientes datos: el nombre de la localidad más cercana a la cuál se encuentran, el nombre del municipio al que pertenece la localidad, y el de la comarca en el cual se encuentran. 
Por otra parte, en cada caso indicaremos, entre paréntesis, la hoja topográfica en donde se sitúa la parada. Para ello, utilizaremos el Mapa Topográfico Nacional (del instituto Geográfico y Catastral). En este caso serán las hojas: 147 (o de Liena), y 179 (o de Bielsa).

Así pues, la relación de las paradas que componen el recorrido de este itinerario, es la siguiente:

PARADA 1 - CONDICIONAL. ANTIGUAS "MINAS DE SERVETO", CAMINO DEL BARRANCO DE MONTILLO, (término municipal de Bielsa, comarca del Sobrarbe). (Hoja 179).

El inicio de este itinerario, cabe realizarlo en Bielsa. Desde ahí, conviene descender ligeramente hacía el Sur por la carretera A-138 (la vieja Hu-640). Mas adelante, hacía las inmediaciones del Km 33, conviene coger un camino que cruza el río Barrosa, descendiendo hasta encontrar el Barranco de Montillo, que habrá de remontar. A unos 3'5-4 Km de Bielsa se encontraran estas minas. Ahí se efectuará la presente parada, después de recorrer esos 3'5 - $4 \mathrm{Km}$.

En este trayecto hacía las "Minas de Serveto", hemos ido encontrando afloramientos de las rocas paleozoicas del Ordoviciense y del Devónico, entre los cuales se encuentran abundantes afloramientos de rocas graníticas. Estos afloramientos pertenecen a los Apilamientos Antiformes de la Zona Axial Pirenaica.

Por lo que concierne a las minas, cabe decir que estas se relacionan con unas mineralizaciones filonianas encajadas entre las rocas graníticas, y entre los materiales devónicos. Entre los minerales presentes se encuentran los siguientes minerales primarios: CALCOPIRITA, ESFALERITA, GALENA, PIRITA, CALCITA, DOLOMITA, BARITINA y CUARZO.

Asimismo, se encuentran también diversos minerales de alteración (formados a partir de los anteriores): GOETHITA (terrosa y limonítica), HEMATITES, AZURITA, CERUSITA y MALAQUITA, entre otros minerales.

PARADA 2 - CONDICIONAL. ENCRUCIJADA DE LA CARRETERA A PLAN CON EL CAMINO HACÍA LA ANTIGUA COLONIA, (Salinas de Sin y Salinas de Bielsa, respectivamente de los términos municipales de TellaSin y de Bielsa, comarca del Sobrarbe). (Hoja 179).

Desde la parada anterior, conviene retornar a la carretera A-138, con la intención de llegar hasta Salinas (Salinas de Sin y Salinas de Bielsa). Se halla en el cruce de las carreteras A-139 (por la que hemos venido) y A-2609 (por la que seguiremos). Así, hay que coger la segunda carretera, hasta llegar a otra cercana encrucijada, de la que sale el ramal que se encamina hacía la Antigua Colonia de IBERDUERO. Ahí, es donde efectuaremos la presente parada, a unos $10 \mathrm{Km}$ de la anterior. 
En este breve recorrido, de unos $2 \mathrm{Km}$, hemos empezado a encontrar afloramientos de los niveles arcillosos y yesosos pertenecientes al Keuper. Estos son precisamente los materiales que se hallan donde ahora estamos. Sin embargo, es muy difícil ver estos materiales, por hallarse recubiertos por derrubios de pendiente y por sedimentos aportados por el río Cinca y por el Cinqueta.

El nombre de "Salinas" no hace referencia a la existencia de ningún aprovechamiento de sal. Obedece a que era un punto de intercambio entre la sal procedente de Naval y los productos mineros. Es decir era un mercadillo, en donde se suministraba sal a los mineros y a sus familias.

En este lugar, pero, había una antigua farga, ciertamente muy importante. Ahí se procesaban los minerales hierro extraídos en diversos lugares de las cuencas del Cinca (Minas del Mener) y del Cinqueta (Minas del Hospital de Gistain). Sin embargo, la farga quedó destrozada en una riada del Cinqueta.

\section{PARADA 3. CRUCE DE SIN Y SERVETO, (término municipal de Plan, comarca del Sobrarbe). (Hoja 179).}

Después de realizarse la parada anterior, hay que continuar hacía el Este, siguiendo por la carretera autonómica antes mencionada (la A-2609). Por ella, se llegará pronto al cruce de la carretera que conduce (por la derecha) al pueblo de Saravillo; y poco después al cruce de la carretera de Sin y Serveto (por la izquierda) En las cercanías de este cruce haremos una nueva parada, a unos $5 \mathrm{Km}$ de la anterior.

En este recorrido, efectuado entre afloramientos de los materiales mesozoicos del Manto de Cotiella, habremos visto abundantes afloramientos de rocas carbonatadas cretácicas, cubiertas de depósitos de piedemonte. Precisamente, desde este lugar mirando hacía la otra parte del Cinqueta, se ve como la carretera de Sin serpentea entre un gran afloramiento de derrubios de pendiente, de grandes dimensiones. Y precisamente puede observarse el peligro que hay ahí de derrumbes sobre la carretera.

PARADA 4. LA INCLUSA, (término municipal de Plan, comarca del Sobrarbe). (Hoja 179).

Después de realizarse la parada anterior, hay que continuar hacía el Este, siguiendo por la carretera autonómica antes mencionada. Por ella, se llegará pronto al Congosto de la Inclusa. En este tramo efectuaremos una nueva parada, sin distribución concreta: puede ser al principio, en un ensanche de la carretera (a medio recorrido), o en el Puente sobre el Cinqueta. Así, desde la parada anterior, habremos recorrido unos $3-4 \mathrm{Km}$, según el lugar de la parada.

En este recorrido, habremos atravesado el Congosto de la Inclusa, un paso abierto por el río Cinqueta entre los materiales carbonatados cretácicos del Manto de Cotiella. Se trata de un interesante congosto, especialmente teniendo en cuenta los desprendimientos de las paredes sobre el río, taponándolo. Aunque el río se ha abierto paso entre los cascotes desprendidos. 


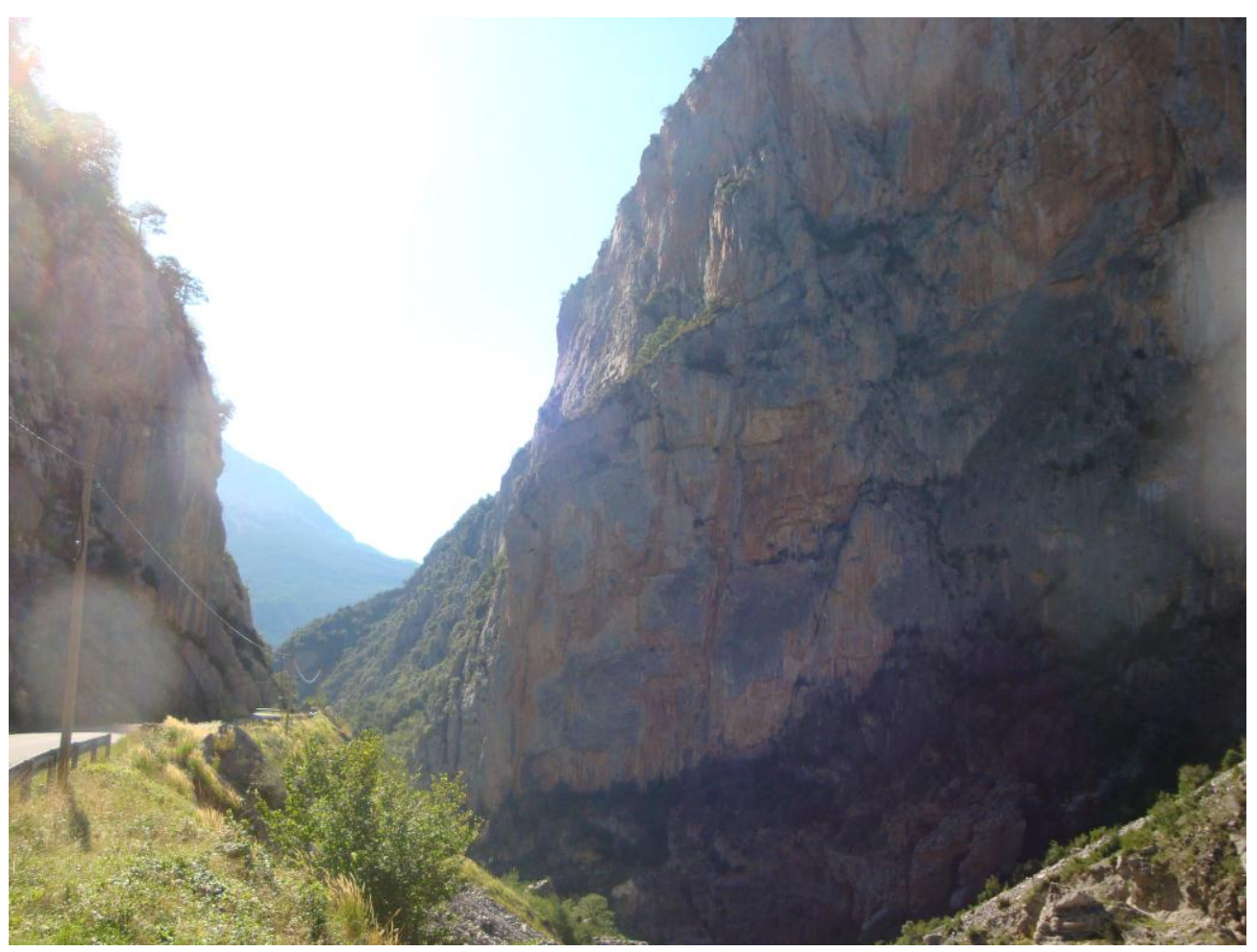

El Congosto desde la carretera

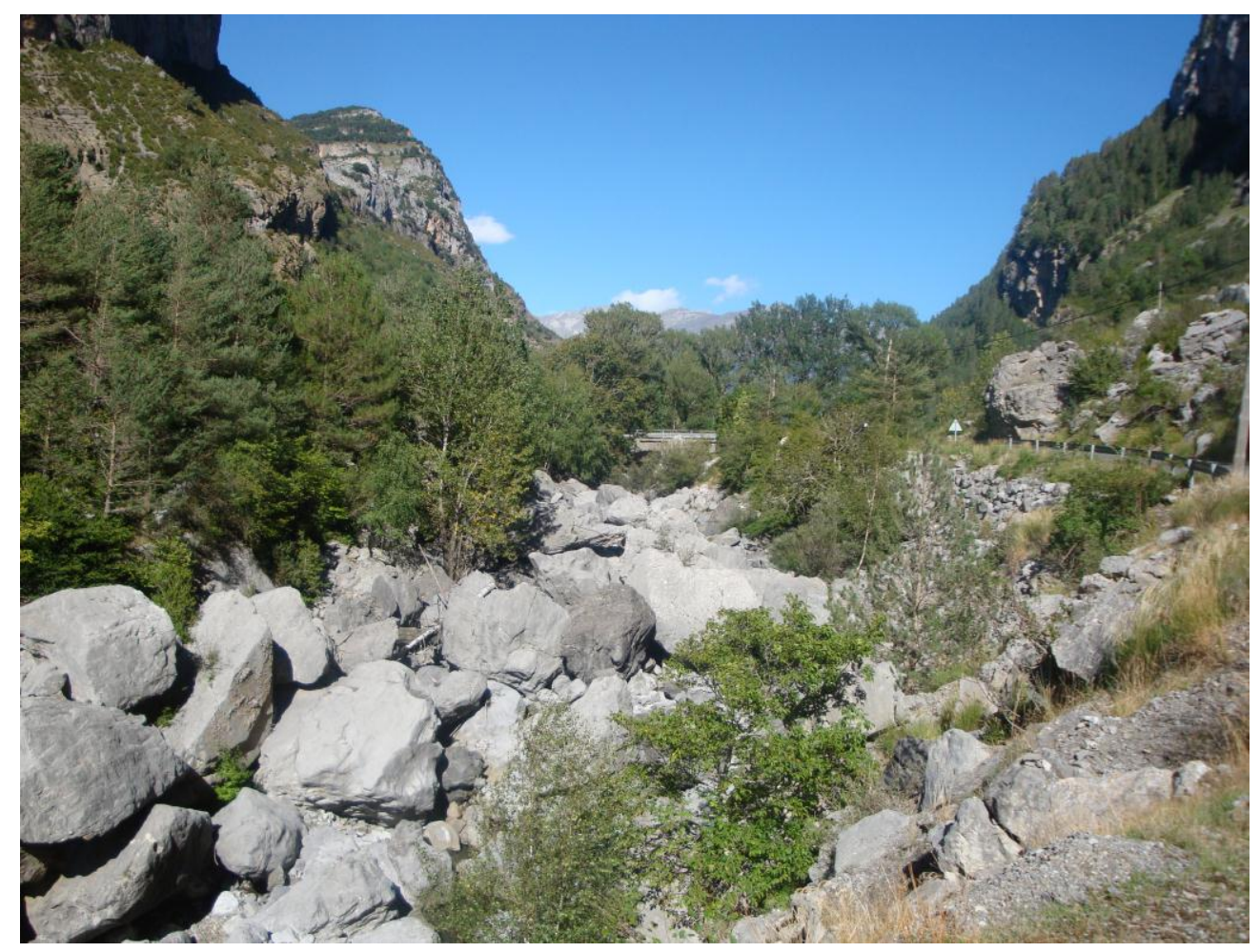

El Cinqueta taponado

Cabe decir que este lugar, es un interesante valor del Patrimonio Geológico de la comarca del Sobrarbe, desde nuestro punto de vista 
PARADA 5. PLANDESCUN, (término municipal de Plan, comarca del Sobrarbe). (Hoja 179).

Después de realizarse la parada anterior, hay que continuar hacía el Este, siguiendo por la carretera autonómica antes mencionada, la A-2609. Por ella, se remontará el Embalse de Pladescun. Más arriba, cerca de Plan, se llegará al llano de Plandescun. (valga la reabundancia). En este lugar, a unos $3 \mathrm{Km}$ de la parada anterior, se puede efectuar otra, ya muy cerca del pueblo de Plan.

Tras la parada anterior, habremos encontrado una antigua explotación de las calizas cretácicas, al otro lado del puente. Luego, más arriba, habremos encontrado una planicie (el "Plandescun"). Se trata de una antigua laguna colmatada por los sedimentos del río Cinqueta.

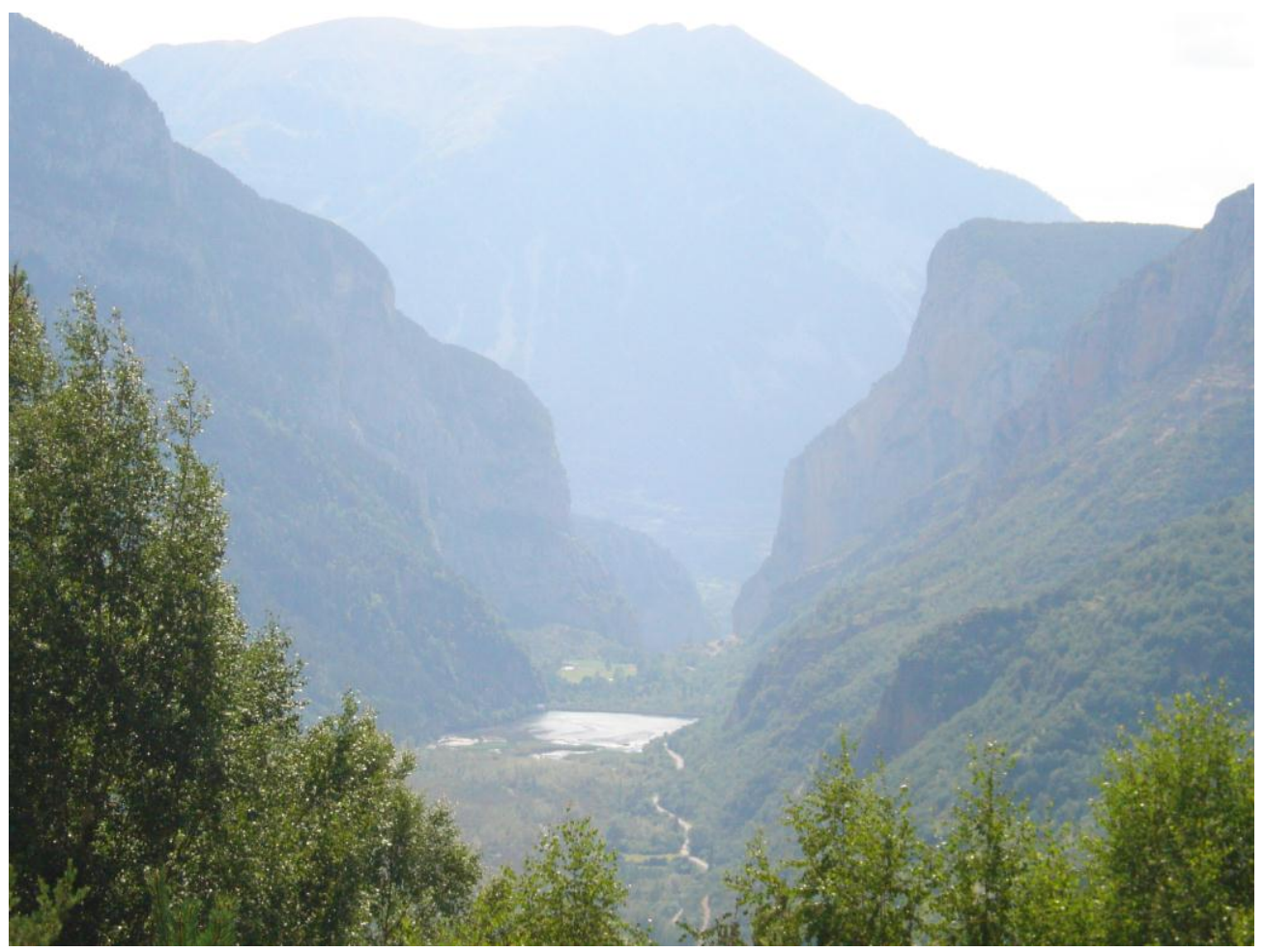

El Valle de Chistau (el llano de Plandescun y el embalse) desde las Minas del Yerri

PARADA 6. ANTIGUAS MINAS DE Co - Ni DEL YERRI, (término municipal de San Juan de Plan, comarca del Sobrarbe). (Hoja 179).

Después de realizarse la parada anterior, hay que continuar remontando el río Cinqueta. Así pronto se llegará a Plan y poco después a San Juan de Plan. Desde aquí habrá que tomar el camino que sale de las inmediaciones del Puente de Pescadores, Este camino va subiendo por la cuesta de San Mamés, llegando luego al Barranco Piscina. Mas adelante, cerca de los Prados de Puyarruego, convendrá tomar un sendero que en media hora nos lleva a las antiguas minas. Ahí efectuaremos una nueva parada, a unos $10 \mathrm{Km}$ de la anteriormente efectuada. 
Buena parte de este recorrido lo habremos efectuado entre afloramientos de materiales paleozoicos (fundamentalmente del Devónico). En efecto, en Plan hemos dejado atrás el Manto del Cotiella y hemos entrado en la zona de Apilamientos Antiformes de la Zona Axial Pirenaica. Estos materiales paleozoicos los iremos encontrando hasta el lugar en donde están las minas.

Las minas se relacionan con una mineralización en parte filoniana y en parte estratiforme, desarrollada entre los niveles carbonatados del Devónico. En este lugar, los minerales de cobalto (y también los de níquel) forman hiladas entre las masas de ANQUERITA y SIDERITA

El mineral de cobalto más abundante es la COBALTINA. Ésta aparece acompañada de diversos minerales minoritarios como los siguientes: ESMALTINA, GERSDORFITA, SKUTTERUDIA i ULLMANITA. Entre los minerales de alteración cabe mencionar los siguientes: HETEROGENITA y ERITRINA

Por lo que concierne a los minerales de níquel (mucho más minoritarios) cabe mencionar la presencia de NIQUELINA, muy a menudo alterada a ANABERGITA y a CABRERITA.

Por otra parte, junto a los anteriores se han encontrado otros minerales como los siguientes: CALCOPIRITA, PIRITA, CALCITA (a menudo cobaltonífera) y CUARZO. Asimismo, otros minerales minoritarios presentes son el BISMUTO y la BISMUTINITA.

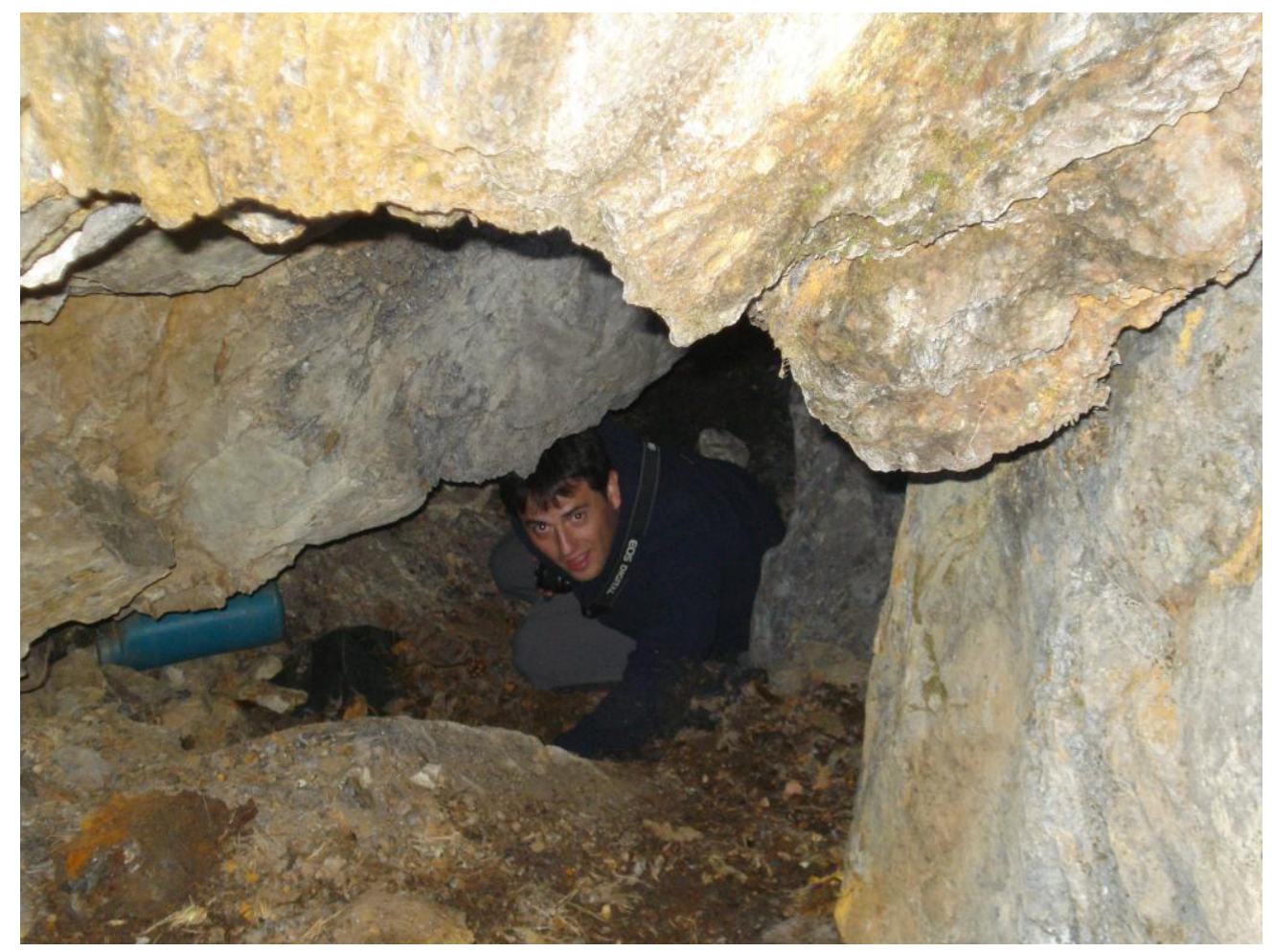

Una de las bocaminas

Por lo que concierne a las bocaminas, cabe considerar que solo una de ellas es accesible. Finalmente, conviene decir que estas mineralizaciones, dada su rareza, son una parte importante del Patrimonio Geológico del Sobrarbe. 


\section{PARADA 7. DESCARGADOR Y FUNDICIÓN DE LAS MINAS DEL YERRI, (término municipal de Plan, comarca del Sobrarbe). (Hoja 179).}

Desde de realizar la parada anterior, conviene (mejor a pie) ir al descargador fundición de las Minas del Yerri. Este se encuentra a unos 1'2 Km, en el Barranco del Sen. Por supuesto, también puede accederse en vehículo, descendiendo a la pista y continuándola hasta este lugar.

En este recorrido habremos ido encontrando los materiales citados en la parada anterior, situados dentro de los Apilamientos Antiformes de la Zona Axial Pirenaica, en donde continuamos.

En este lugar hay los restos de los edificios del descargador y la antigua fundición detestas minas. Se hallan muy destruidos por las acciones devastadoras del mencionado Barranco del Sen. Precisamente, junto a los restos mineros se halla una presa correctora del torrente.

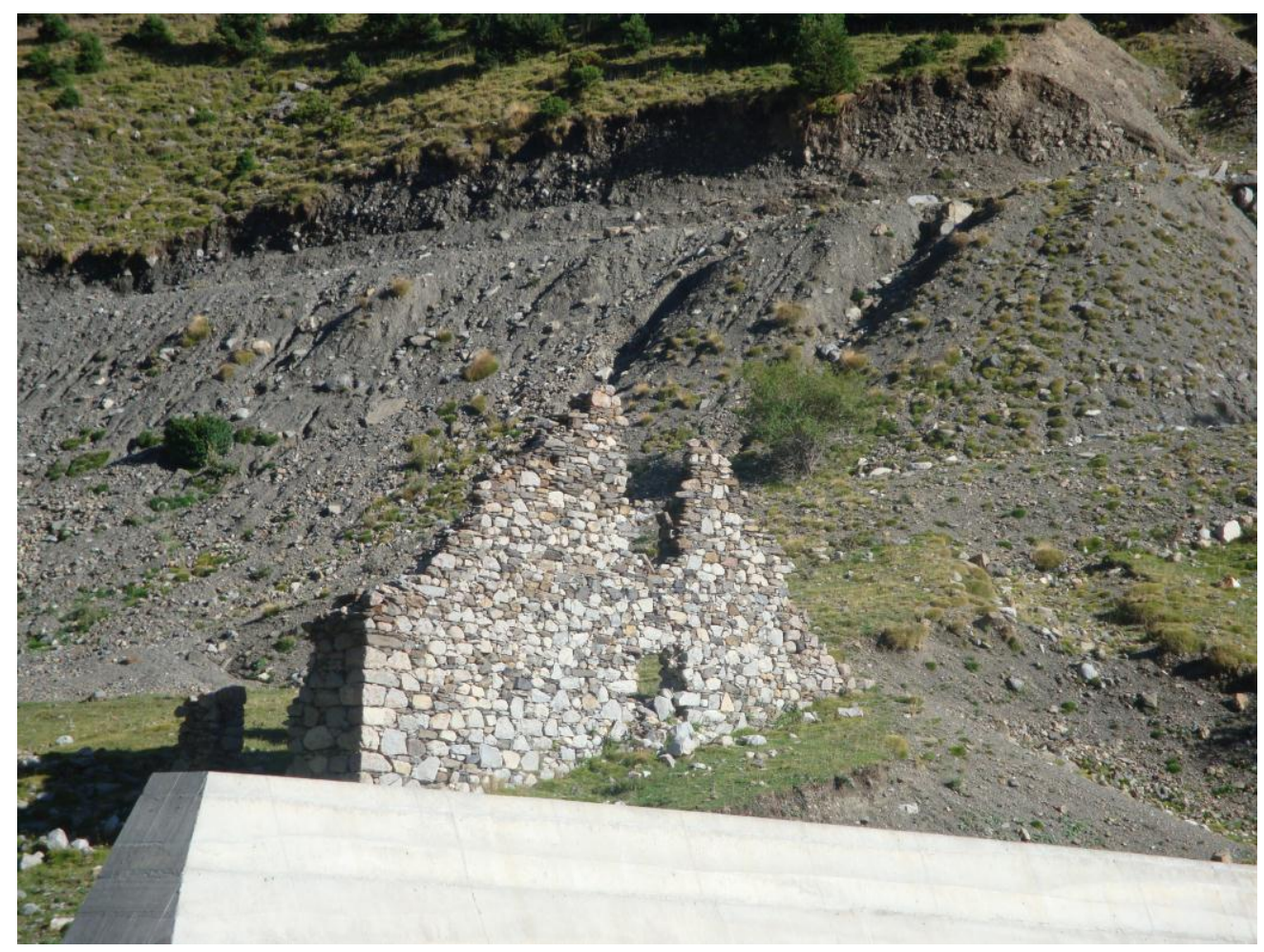

La presa y los restos mineros

PARADA 8 - CONDICIONAL. GARGANTAS DEL ESPITAL, (Hospital de Gistaín, términos municipales de Gistaín y de San Juan de Plan, comarca del Sobrarbe). (Hoja 179).

Des de la parada anterior, es necesario retornar a San Juan de Plan, para remontar el río Cinqueta desde ahí, hacía el Hospital de Gistaín. Así, pronto dejaremos la carretera que asciende hacía el pueblo de Gistaín. A partir de aquí el camino será de tierra, con algunos tramos cementados, Por este camino pasaremos por lugares como: las Cascadas de las Gorcillas, la Pedreña, las Feixas, el Grau, ... llegando finalmente a las 
Gargantas del Espital. Ahí haremos una nueva parada, a unos $8 \mathrm{Km}$ de Plan y a unos 15 de la parada anterior.

En este recorrido hemos ido siempre remontando el río Cinqueta, entre afloramientos de los materiales paleozoicos mencionados en las paradas anteriores. Aunque a menudo, estos materiales se hallan recubiertos por derrubios de pendiente, por depósitos morrénicos y por depósitos fluviales.

En este lugar hay un interesante congosto, abierto por el río Cinca al atravesar los materiales carbonatados del Devónico.

PARADA 9. MINAS DE PLOMO - ZINC DEL HOSPITAL DE GISTAÍN, (Hospital de Gistaín, término municipal de Gistaín, comarca del Sobrarbe). (Hoja 179).

Después de realizar la parada anterior, nos conviene seguir remontando el Cinqueta, llegando pronto al Hospital de Gistain. Desde aquí, nos conviene remontar el Barranco de la Sargueta, hasta encontrar las minas, en donde realizaremos la última parada de este itinerario, a unos $4 \mathrm{Km}$ de la anterior.

Como en el caso anterior, este recorrido se habrá efectuado entre afloramientos de los materiales paleozoicos, fundamentalmente del Devónico. Sin embargo, cerca del lugar de la parada encontraremos también afloramientos calcoesquistosos del Ordovícico, en contacto con granitos.

La mineralización es filoniana, situándose entre los materiales del Devónico. Los minerales presentes son: ESFALERITA, GALENA, PIRITA y QUARS. Asimismo, junto a ellos también se encuentran indicios de otros minerales como FLUORITA y CALCOPIRITA.

EN ESTE LUGAR FINALIZA EL ITINERARIO

\section{BIBLIOGRAFÍA}

CALVO, M. et altri (1988). - Minerales de Aragón, Colección Temas Geológicos, 207 Pág. Zaragoza

GUIMERÀ, J. et altri (1992).- Geologia (II). Història Natural dels Països Catalans. Vol. 2, 547 pag. Enciclopedia Catalana, S.A. Barcelona

GOBIERNO DE ARAGÓN (2001).- Puntos de Interés Geológico de Aragón. Consejería de Medio Ambiente del Gobierno de Aragón. Zaragoza 
IGME (1972).- Mapa Geológico de España a escala 1:200.000 (Síntesis de la cartografía existente). Hoja y Memoria nº 23 (Huesca). Inst. Geol. Min. España

IGME (1973).- Mapa Metalogenético de España a escala 1:200.000. Hoja y Memoria n'. 23 (Huesca). Inst. Geol. Min. España

IGME (1975).- Mapa de Rocas Industriales de España a escala 1:200.000. Hoja y Memoria $n^{\circ} .23$ (Huesca). Inst. Geol. Min. España

MAESTRE, A. (1845).- Descripción geognóstica del Distrito Minero de Cataluña y Aragón. Anales de Minas, t. III. Madrid

MATA - PERELLÓ, J.; (1987).- Introducción al conocimiento de las mineralizaciones aragonesas. Mineralogistes de Catalunya, t.III, pp. 258-265. Barcelona

MATA - PERELLÓ, J.M. (1992).- Inventario Mineralógico de la comarca del Sobrarbe. Rodeno, 13. 42 Pág. Manresa

MATA-PERELLÓ, J.M. (1995).- Itinerario geológico-mineralógico por la comarca del Alto Sobrarbe: desde Bielsa a Plan y a Chistén. Xaragall, série B, nº 20, 15 pag. Manresa

MATA-PERELLÓ, J.M. (1996).- Itinerari geològic-mineralògic per la Ball de Benás i per la Bal de Chistau: des d'Erist a Plan i a Chistén. Xaragall, sèrie B (en premsa). 10 pàg. Manresa

MATA-PERELLÓ, J.M. (1997a).- Recorregut de recerca geològica i mineralògica per les comarques del Semontano i de l'Alto Sobrarbe: des de Barbastro a Bielsa, per Naval i l’Ainsa. Algeps, sèrie B (en premsa), 9 pàgines. Manresa

MATA-PERELLÓ. J.M. (1997b).- Recorregut de recerca geològica i mineralògica per les comarques de l'Alto Sobrarbe i de la Ball de Benàs: des de Bielsa a Plan, i des de Chistén al Portilló de Benàs. Algeps, sèrie B (en premsa), 9 pàg. Manresa

MATA - PERELLÓ, J.M. (2007).- Itinerario geológico y mineralógico por la comarca del Alto Sobrarbe: desde Bielsa a Parzán y al Valle de Pineta. Recorrido por el patrimonio minero del Alto Sobrarbe. Inédito. 10 pag. Manresa

MATA - PERELLÓ, J.M. y SANZ-BALAGUË, J. (1992).- Guía de Identificación de Minerales, adaptada fundamentalmente a la Península Ibérica. Edic. Parcir, 243 pag. Manresa

PRAMES (2005).- Sobrarbe. Colección RUTASCAL por Aragón. Prames, Gobierno de Aragón. 119 pag. Zaragoza.

VIVEZ, Ph. (1997a).- Un centro industrial en el término de Bielsa: el Hospital de Parzán. Actividades transfronterizas para la explotación del plomo argentífero desde finales del S. XIX hasta principios del s. XX. Ayunt. de Bielsa (relaciones históricas del Valle de Bielsa con Francia). pp. 37-61. Bielsa 
VIVEZ, Ph (1997b).- Minas del Hospital de Parzán. Ayunt. de Bielsa (relaciones históricas del Valle de Bielsa con Francia). pp. 63-95. Bielsa 